\title{
Evaluation Eucalyptus camaldulensis Contaminations with Cryptococcus gattii in Tehran
}

Roohollah Fateh ${ }^{1}$, Mahnaz Dehghani Pour ${ }^{2}$, Farideh Zaini $^{3}$, Maasoumeh Mahdavi-Ourtakand ${ }^{2}$, Zahra Salehi $^{4}$, Mona Ghazanfari ${ }^{5}$, Shirin Farahyar ${ }^{5}$, Samira Salari ${ }^{6,7}$, Azam Fattahi $^{8}$

1. Department of Microbiology and Immunology, School of Medicine, Qom University of Medical Sciences, Qom. Iran

2. Department of Biology, School of Biological Sciences, Varamin-Pishva Branch, Islamic Azad University, Varamin, Iran

3. Department of Medical Mycology and Parasitology, School of Medicine, Tehran University of Medical Sciences, Tehran, Iran

4. Department of Mycology, School of Medicine, Tarbiat Modarress University, Tehran, Iran

5. Department of Medical Mycology and Parasitology, Faculty of Medicine, Iran University of Medical Sciences, Tehran, Iran

6. Research Center for Tropical and Infectious Diseases, Kerman University of Medical Sciences, Kerman, Iran

7. Department of Medical Mycology and Parasitology, School of Medicine, Medical University of Kerman, Kerman, Iran

8. Research Center of Pediatric Infectious Diseases, Institute of Immunology and Infectious Diseases, Iran University of Medical Sciences, Tehran, Iran

\section{Article Information}

Article history:

Received: 2018/02/16

Accepted: 2018/04/16

Available online: 2018/06/30

Article Subject:

Clinical Mycology

IJMM 2018; 12(2): 133-139

Corresponding author:

Azam Fattahi

Research Center of Pediatric

Infectious Diseases, Institute of

Immunology and Infectious

Diseases, Iran University of

Medical Sciences, Tehran, Iran

Tel: 09125272567

Email:

Fattahiazam63@gmail.com

Use your device to scan and read the article online

\section{Abstract}

Background and Aims: Cryptococcosis is an infection caused by Cryptococcus species. Cryptococcus gattii is mostly isolated from Eucalyptus trees and is acquired via inhalation of basidiospores. The present study was performed to isolate Cryptococcus sp. from Eucalyptus trees and evaluate C. gatti contamination of the Eucalyptus camaldulensis trees in some parks of Tehran and Varamin.

Materials and Methods: 88 trees (leaves, stalk, fruit and soil) were collected from different areas of Tehran, Varamin and Shahr Ray in 2014-2015 during spring and fall. Identification of Cryptococcus sp. were performed based on colony color on niger seed agar medium, urease production, india ink test and pseudohyphae formation on corn meal agar with tween 80. Specific differentiation of Cryptococcus sp. were performed using sugar assimilation by API 20C AUX, disk approaches, colony color on Canavanine Glycine Bromothymol Blue and Cycloheximide-Phenol Red Agar medium.

Results and Conclusions: 6 out of 88 samples of Eucalyptus trees were identified as Cryptococcus sp. Accordingly, four species were identified as Cryptococcus albidus while species of two other isolates were not detectable by used methods. Although Cryptococcus gattii was not isolated from the collected samples, this does not mean that Eucalyptus trees of Tehran are not contaminated.

Keywords: Eucalyptus camaldulensis, Contamination, Cryptococcus gattii, Tehran

Copyright $\odot 2018$ Iranian Journal of Medical Microbiology. All rights reserved.

How to cite this article:

Fateh R, Dehghani pour M, Zaini F, Mahdavi-Ourtakand M, Salehi Z, Ghazanfari M, et al Evaluation Eucalyptus camaldulensis Contaminations with Cryptococcus gattii in Tehran Provience, Iran. Iran J Med Microbiol. 2018; 12 (2): 133-139 


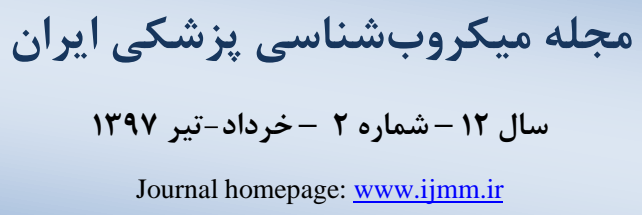

\section{بررسى درختان /وكالييتوس كامالدولنسيس از نظر آلودكى به كريِّوكوكوس كتى در استان تهران}

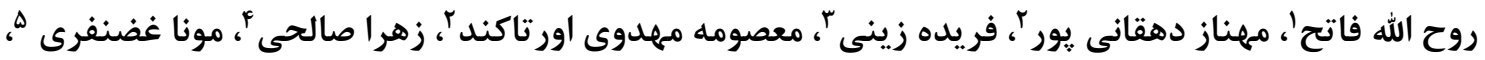

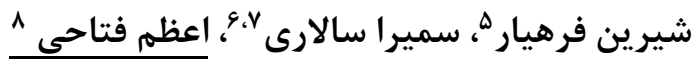

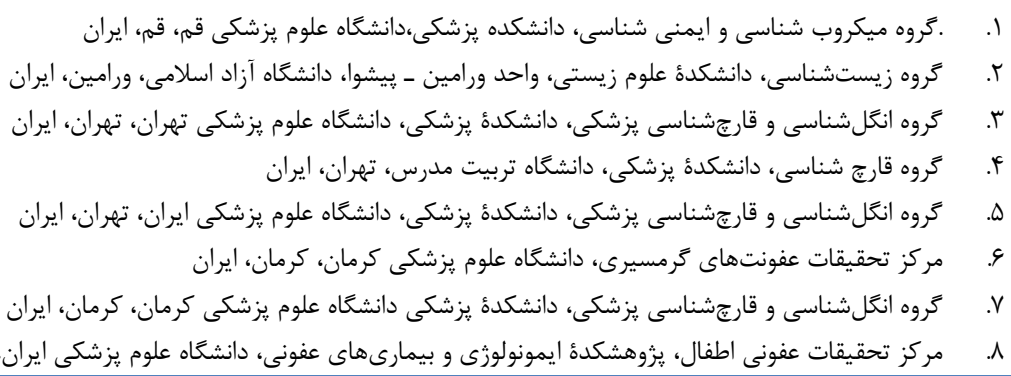

\section{جكسبـ}

زمينه و هدف: كرييتوكوكوزيس توسط كونههاى مختلف قارج كرييتوكوكوس ايجاد مىشود. كريبتوكوكوس كتى عمدتاً از

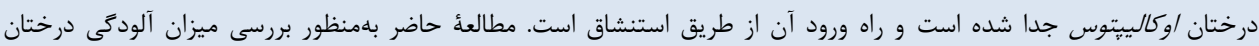

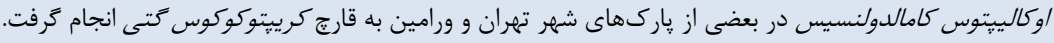

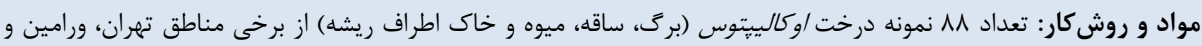

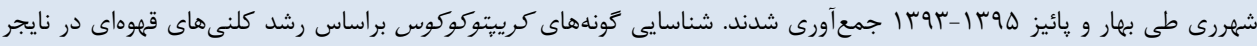

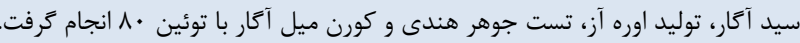

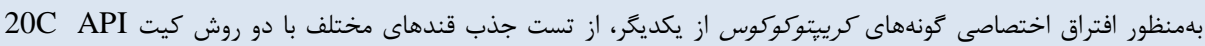

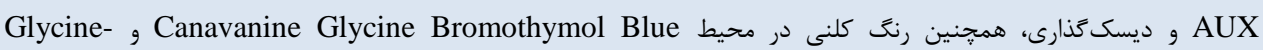
Cycloheximide-Phenol Red يافتهها و بحث: از مجموع \1 نمونهُ جداشده از درخت /وكالييتوس، 9 مخمر از نظر كونههاى كريبتوكوكوس مثبت شدند. از

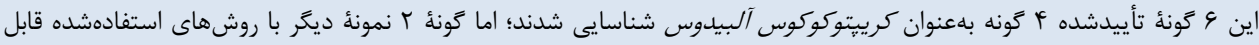

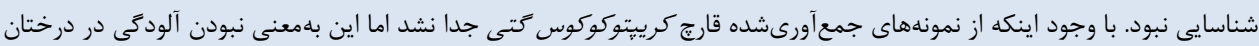

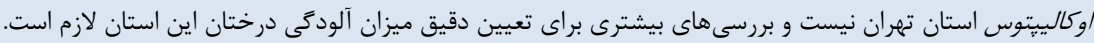

$$
\text { كلمات كليدى:/والييتوس كامالدولنسيس، آلودكى، كريبتوكوكوس كتى، تهران }
$$

كجى رايت C: حق جֶاب، نشر و استفاده علمى از اين مقاله براى مجله ميكروبشناسى بزشكى ايران محفوظ است.
اطلاعات مقاله

تاريخجه مقاله دريافت:

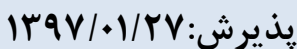

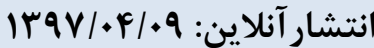
موضوع: قارج شناسى بالينى

IJMM1397;12(2): 133-139

نويسنده مسئول:

$$
\text { اعظم فتاحى }
$$

مركز تحقيقات عفونى اطفال، يروهشكدة

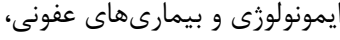
دانشگاه علوم يزشكى ايران، تهران، ايران

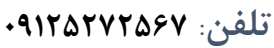
يست الكترونيك:

Fattahiazam63@gmail.com

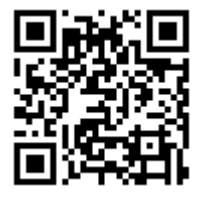

مقدمه

نئوفورمنس دارد و منجر به ايجاد ضايعات مختلفى در ريه و مغز مىشود (ب-1). عفونت ناشى از اين قارج هم در افراد سالم و هم

كرييتوكو كوزيس عفونتى است كه از طريق گونههاى مختلف مخمر بازيديومايست كريبتوكوكوس ايجاد مىشود. كريبتوكوكوس كتى از نظر بالينى بيمارىزايى بيشترى نسبت به كريبتوكوكوس 
هدف از اين مطالعه بررسى ميزان آلودحى درختان /وكالييتوس

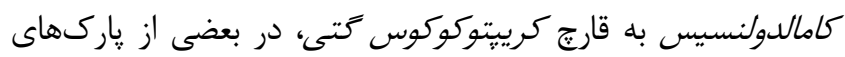

$$
\text { تهران و ورامين است. }
$$

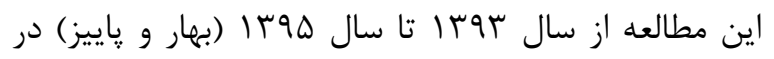

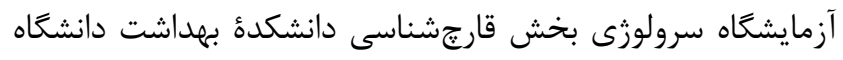

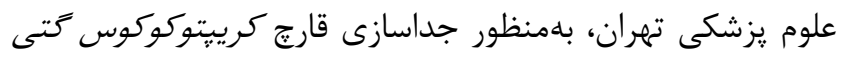

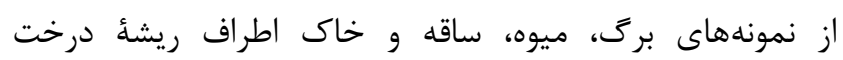

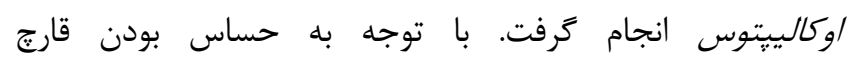

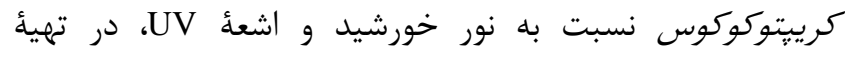

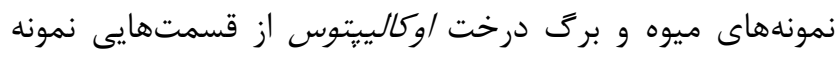

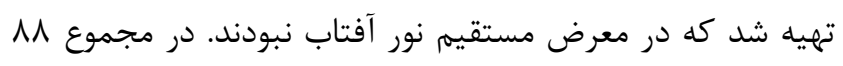

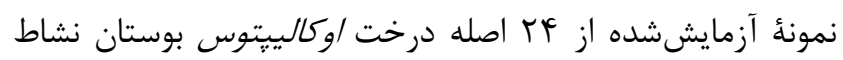

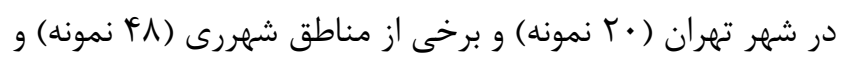

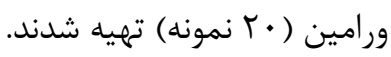

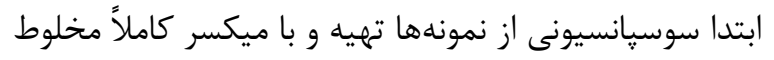

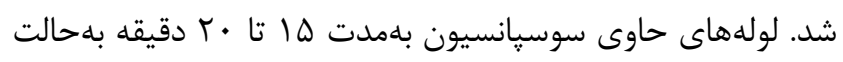

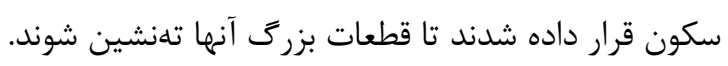

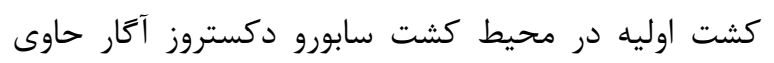

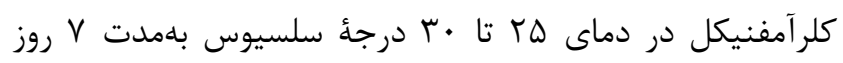

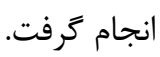

تشخيص اوليأ مخمرها براساس شكل ظاهرى، رنگ و قوام

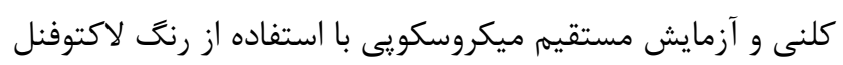

$$
\text { كاتن بلو صورت كرفت. }
$$

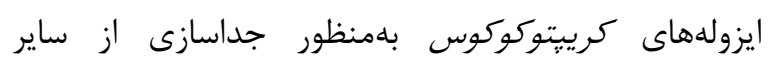

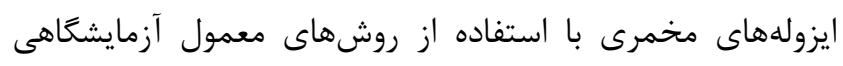

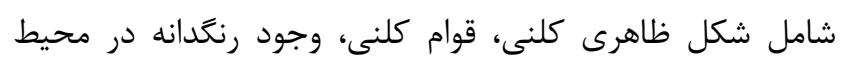

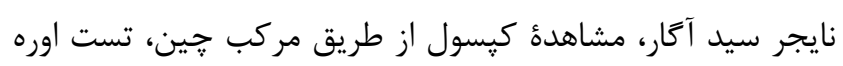

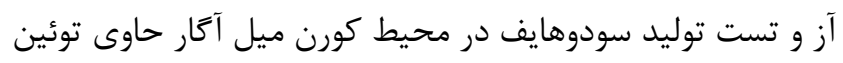

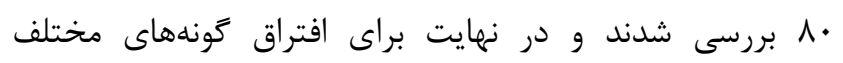

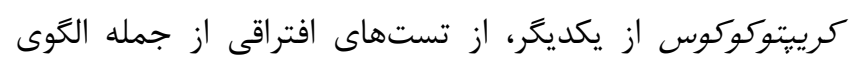

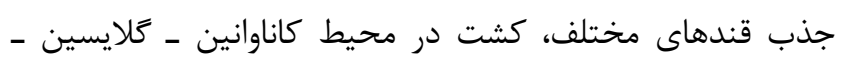

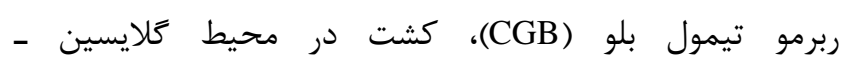
سيكلوهكزاميد ـ فنل رد (GCP) استفاده شد.

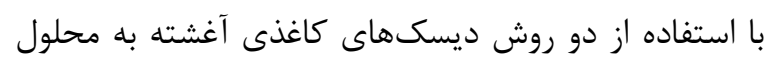

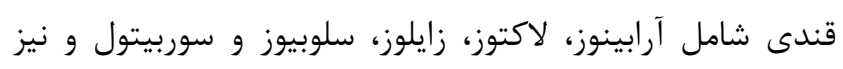

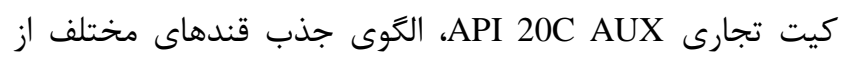
طريق كونهاى مشكوك به قارج كرييتوكوكوس ارزيابى شد.
در افراد دجار نقص ايمنى و نيز حيوانات خانكى مثل سگ، گربه و اسب گزارش شده است.

كريبتوكوكوس نئوفورمنس را براساس ويزگى هاى آنتىزنيك

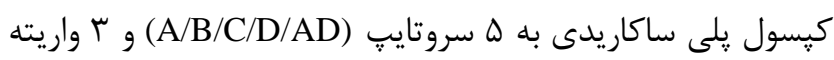

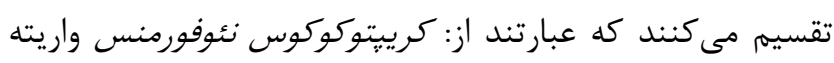

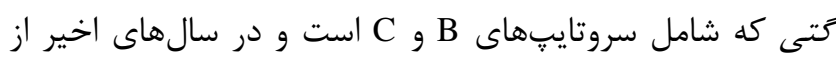

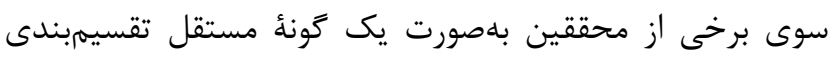

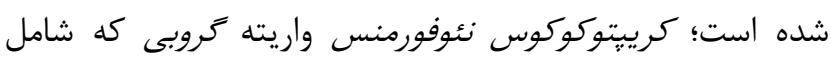

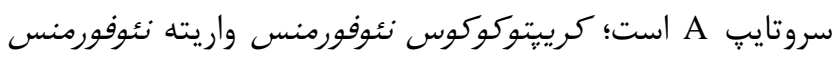

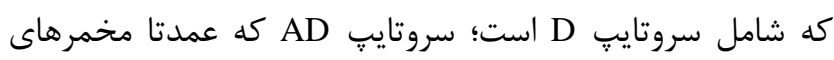

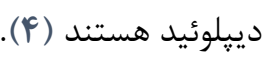

عفونت عمدتا در نواحى گرمسيرى و نيمهَ كرمسيرى كزارش

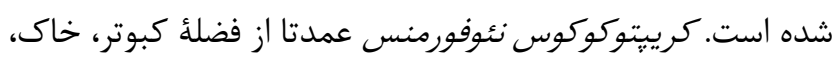

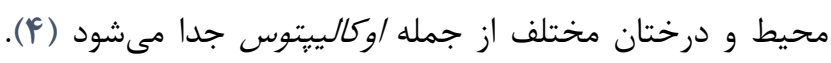

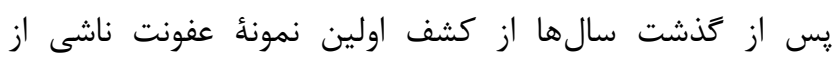

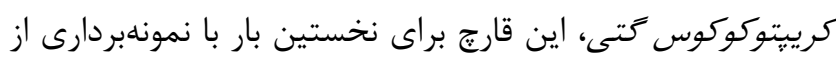

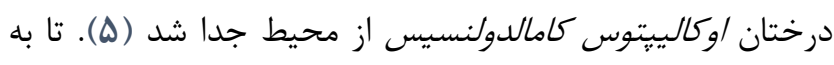

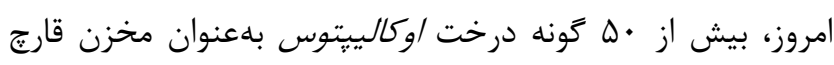

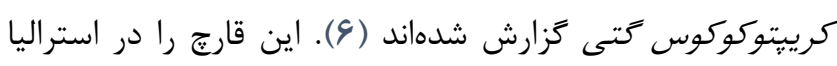

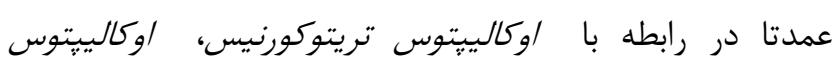

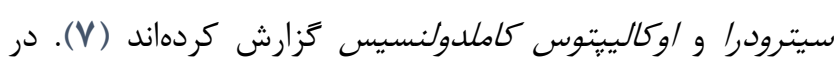

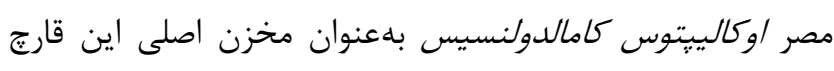

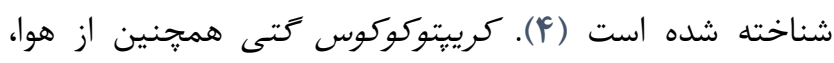

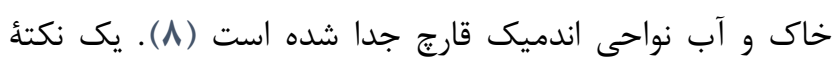

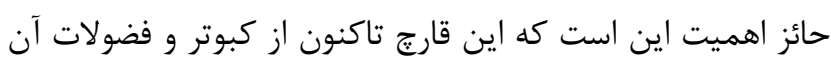

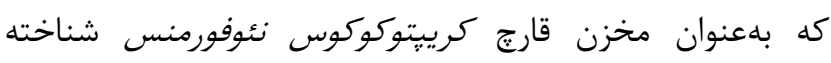

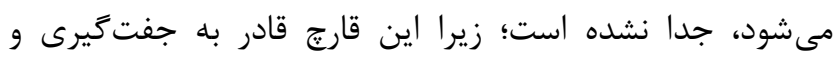

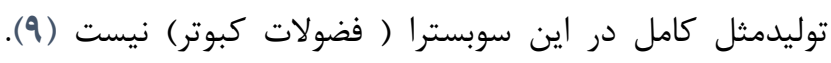

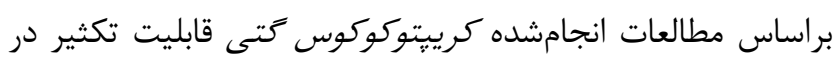

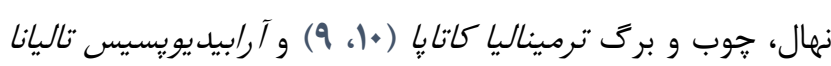

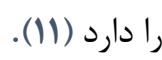

اطلاعات اكولوزيكى در آشكار شدن جنبههاى إيدميولوزيكى (1).

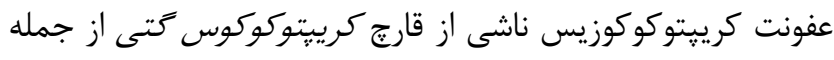

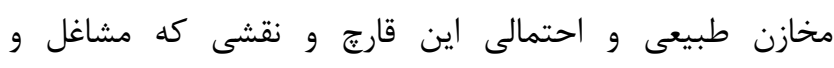

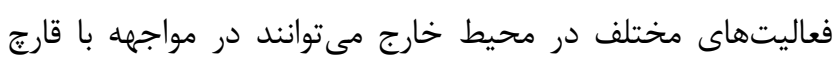

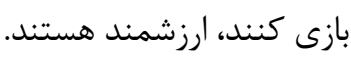


يافتها و بحث

از مجموع اس مخمر بلهدستآمده 9 نمونه براساس تستهاى

تشخيصى و افتراقى مشكوك به كريتِوكوكوس بودند (جدول (1).

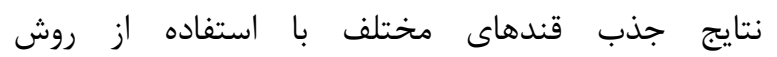
ديسك گذارى و كيت تجارى API 20 AUX در جدول ب و ب آورده

شده است.
در محيطهاى CGB GCP قارج كريبتوكوكوس كتى

بهترتيب قادر به تغيير رنت محيط از زرد به قرمز و زرد به آبى دونى

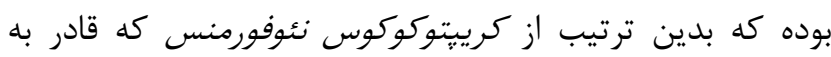
تغيير رنت محيط نيست، افتراق داده مىشد.

جدول شماره ا. نتايج مربوط به تستهاى تشخيصى و افتراقى ايزوله هاى مشكوك به كرييتوكوكوس

\begin{tabular}{|c|c|c|c|c|c|c|c|}
\hline توليد سودوهايف در محيط & GCP & CGB & 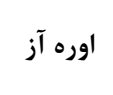 & كلنى قهوهاى در & مركب جين & 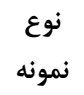 & 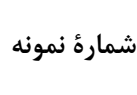 \\
\hline - & - & - & 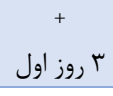 & + & مخمر كروى با كيسول نازك & خاى & 1 \\
\hline- & - & $\begin{array}{c} \pm \\
\%\end{array}$ & 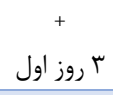 & + & مخمر بادامى شكل و جوانهدار & برى & $r$ \\
\hline - & - & - & + + + + بروز اول & + & مخمر كروى با كيسول نازك & برى & $r$ \\
\hline- & - & - & + ب + ب بوز اول & + & مخمر كروى، جوانهدار با كيسول نازى & خاك & $r$ \\
\hline- & - & $\begin{array}{c} \pm \\
\%\end{array}$ & 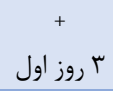 & + & مخمر كروى، جوانهدار با كيسول نازى & ميوه & $\Delta$ \\
\hline- & - & + & $\begin{array}{c}+ \\
+ \\
\end{array}$ & + & مخمر كروى، جوانهدار با كيسول نازى & ساقه & 9 \\
\hline
\end{tabular}

جدول شمارهr. نتايج جذب ه قند مختلف با استفاده از روش ديسك قَذارى

\begin{tabular}{|c|c|c|c|c|c|}
\hline قند سوربيتول & قند سلوبيوز & قند زايلوز & قند لاكتوز & قند آرابينوز & شمارهٔ نمونه \\
\hline+ & + & + & - & + & 1 \\
\hline+ & + & + & + & + & r \\
\hline+ & + & + & + & + & r \\
\hline+ & + & + & - & + & f \\
\hline+ & + & + & - & + & $\Delta$ \\
\hline+ & + & + & $\%$. & $\%$. & \& \\
\hline
\end{tabular}

جدول شماره r. الكوى جذب قندهاى مختلف از طريق ايزوله هاى مشكوى به كرييتوكوكوس

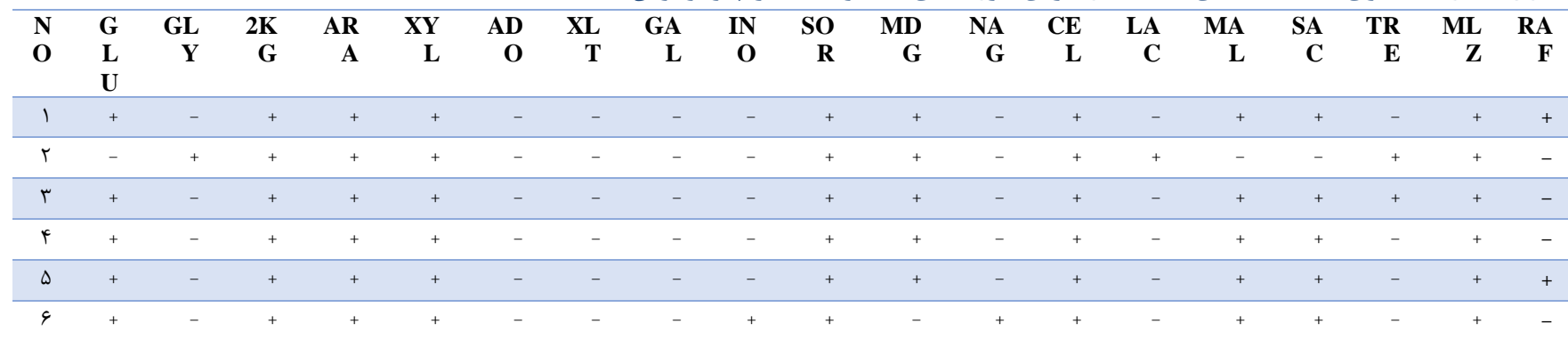

برى و ا نمونه از ميوه) و يك ايزوله از ساقئ درختان اوكالييتوس بوستان نشاط تهران جدا شدند.

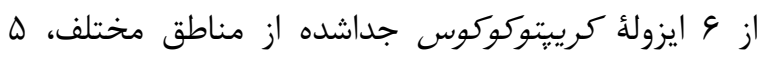

مخمر از درختان اوكالييتوس شهررى (r نمونه از خاك، ب نمونه از 


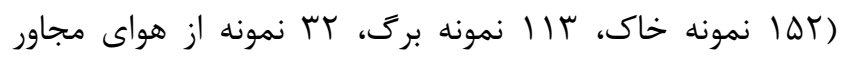

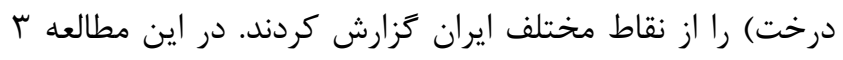

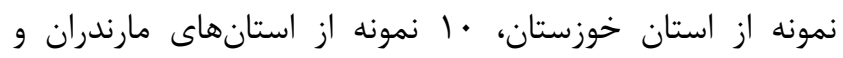

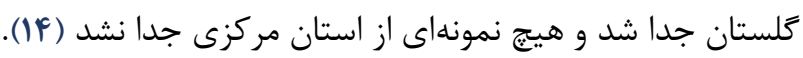

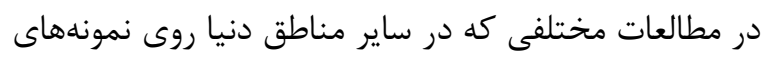

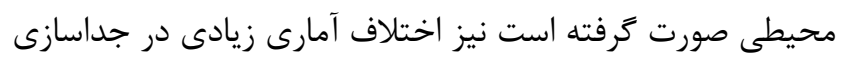

$$
\text { قارج كرييتوكوكوس كتى وجود دارد. }
$$

Zaragozi

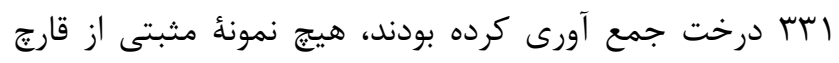

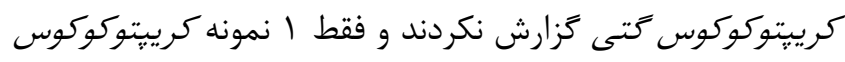

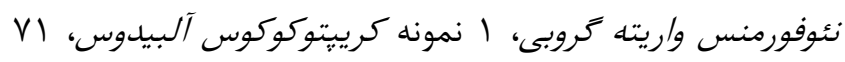

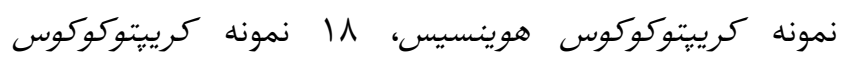

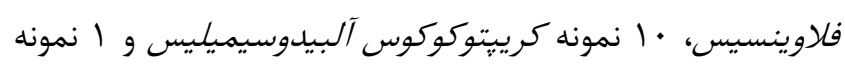

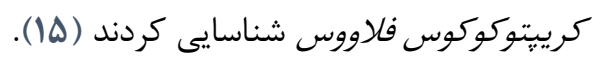

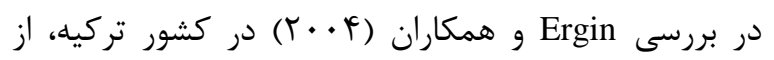

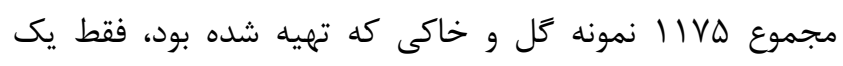

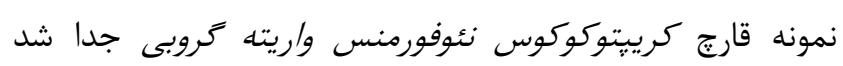

Hamasha

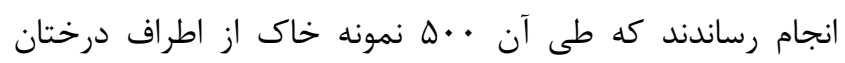

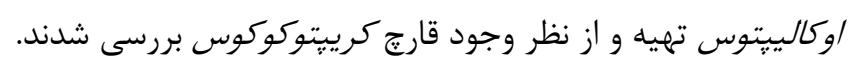

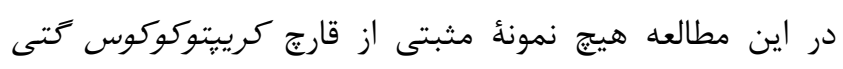

كزارش نشد (IV) - (IV)

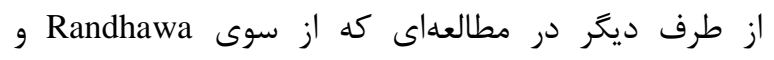

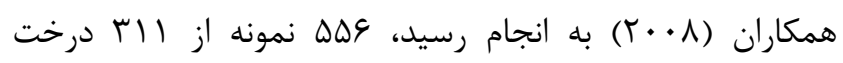

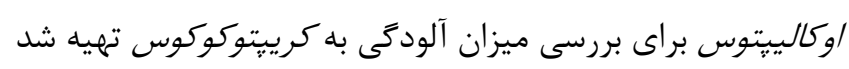

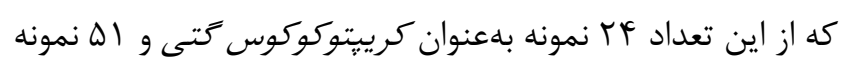

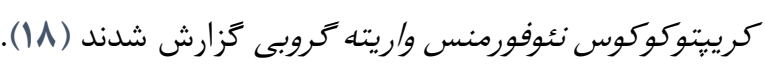

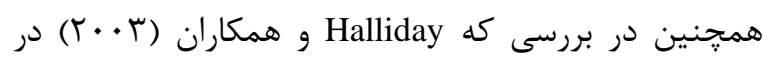

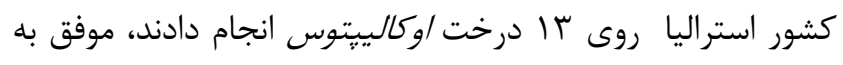

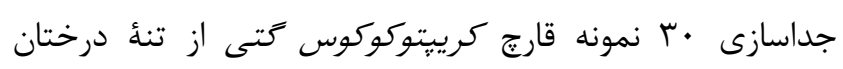

شدند (19).

تفاوت آمارى موجود در مناطق مختلف جهان مىتواند با

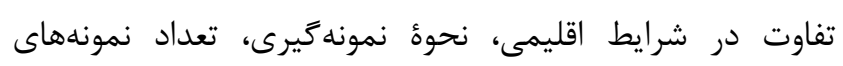

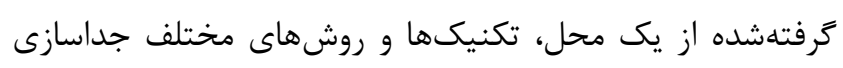
مخمر در ارتباط باشد.

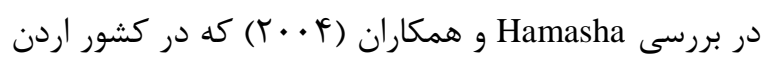

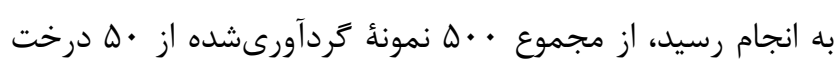

براساس تستهاى مختلف تشخيصى و افتراقى f ا ايزوله،

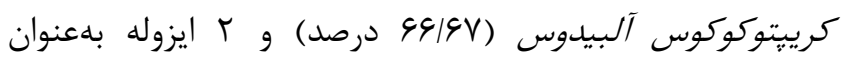

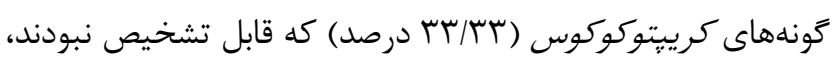
معرفى شدند.

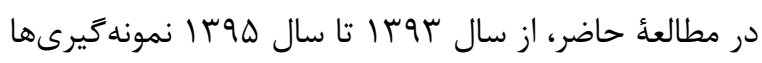

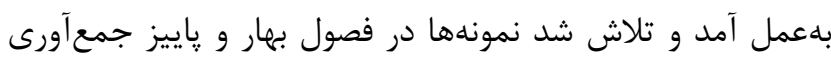

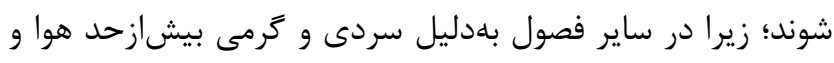

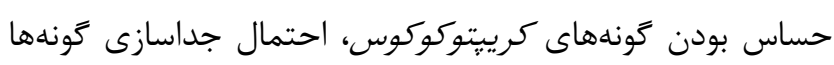

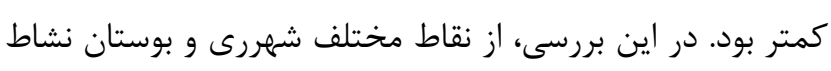

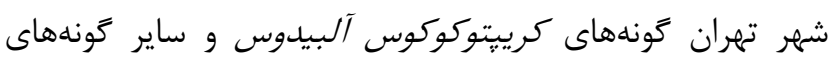

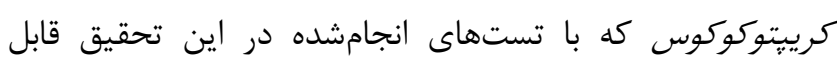
شناسايى نبودند، جدا شدند.

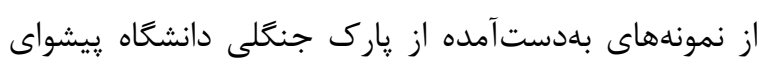

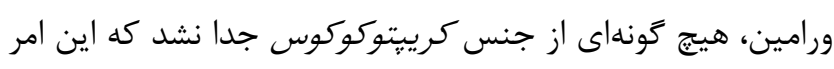

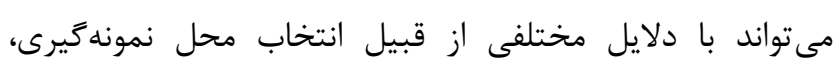
اختلاف درجه حرارت و آبوهواى اين منطقه مرتبط باشد.

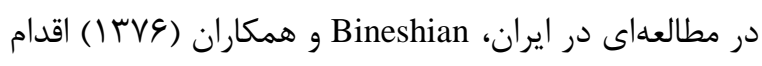
به جداسازى كريبتوكوكوس كتى از گلى، برك، ميوه و و يوست

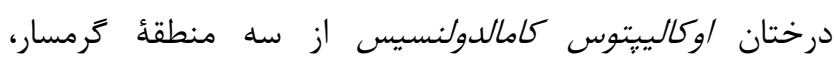

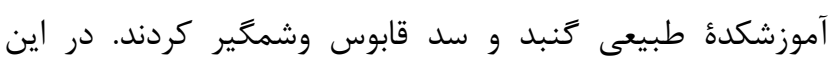

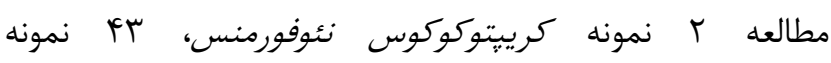

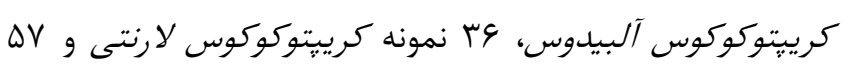

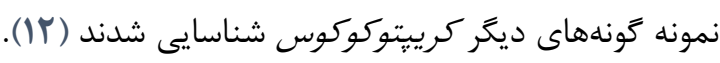

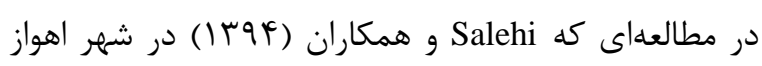

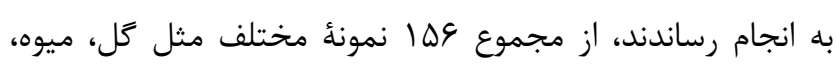

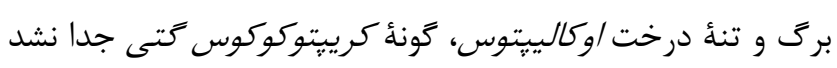

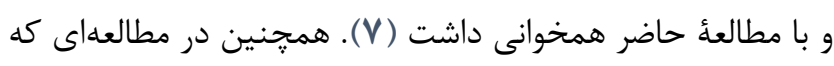
Kamari

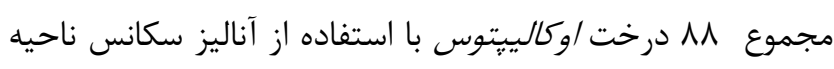

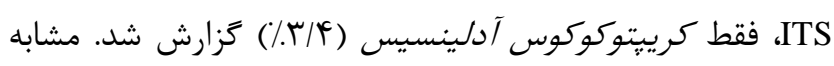

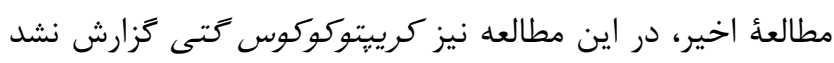

از نظر انتشار جغرافيايى كرييتوكوكوس كتى، اين كونه

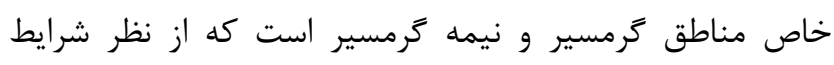

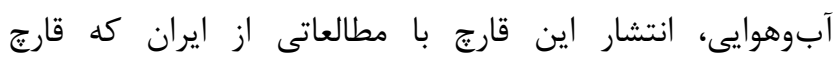

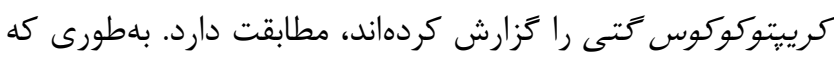
Nowrozi

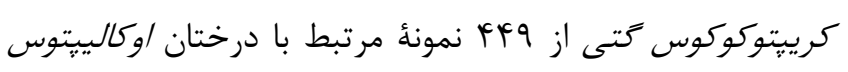


استان را نفى كند. لذا بررسى بيشتر در مناطق بيشترى از استان

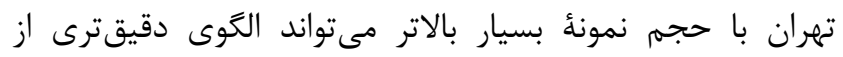

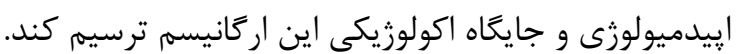
از اين مطالعه مىتوان بهعنوان سنَ بناى اوليه براى بررسى إيدميولوزى و يراكندگى اكولوزيكى قارج كرييتوكوكوس كتى در در استان تهران ياد كرد كه مىتواند مبنايى براى انجام مطالعات بعدى و تكميلىتر در اين زمينه با روشهاى ييشرفتهتر باشد و

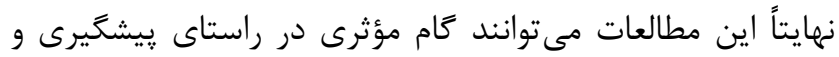
درمان عفونت ناشى از قارج كرييتوكوكوس گتى بردارند كه با توجه به قابليت اين قارج در ايجاد بيمارى در افراد با سيستم ايمنى سالم، بهعنوان يك خطر بالقوهُ بهداشتى محسوب مىشود.

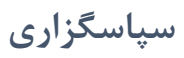

نويسندكان اين مقاله از تمام عزيزانى كه در مراحل انجام اين تحقيق همكارى داشتند، كمال تشكر و قدردانى را دارند.

$$
\text { تعارض منافع }
$$$$
\text { بين نويسندگان تعارض در منافع زَارش نشده است. }
$$

\section{References}

1. . Mitchell DH, Sorrell TC, Allworth AM, Heath $\mathrm{CH}$, McGregor AR, Papanaoum $\mathrm{K}$, et al. Cryptococcal disease of the CNS in immunocompetent hosts: influence of cryptococcal variety on clinical manifestations and outcome. Clin Infect Dis. 1995;20(3):611-6. https://doi.org/10.1093/clinids/20.3.611 PMID:7756484

2. Chen S, Sorrell T, Nimmo G, Speed B, Currie B, Ellis D, et al. Epidemiology and host-and variety-dependent characteristics of infection due to Cryptococcus neoformans in Australia and New Zealand. Clin Infect Dis. 2000;31(2):499-508

https://doi.org/10.1086/313992 PMID: 10987712

3. Galanis E, MacDougall L, Kidd S, Morshed M, Group BCCgW. Epidemiology of Cryptococcus gattii, British Columbia, Canada, 1999-2007. Emerg Infect Dis. 2010;16(2):251-7. https://doi.org/10.3201/eid1602.090900 PMID:20113555 PMCID:PMC2958008

4. Elhariri M, Hamza D, Elhelw R, Refai M. Eucalyptus tree: a potential source of Cryptococcus neoformans in Egyptian environment. Int J Microbiol. 2016;2016(1):1-5. https://doi.org/10.1155/2016/4080725 PMID:26884765 PMCID:PMC4738708
اوكاليتِوس، عץا قارج كرييتوكوكوس جدا شد كه در تمامى آنها كيسول مشاهده شد. همجنين در تمام گونهها تست اوره آز مثبت

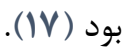

از بين 4 كونه كرييتوكوكوس بهدستآمده در اين مطالعه، ه

كونه از درختان اوكالييتوس منطقهُ شهررى جدا شدند و فقط يك كونه مربوط به بوستان نشاط شهر تهران بود. اين موضوع شايد

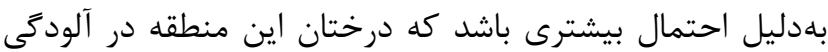
به گونههاى كريبتوكوكوس مى توانند داشته باشند. بهطور مثال حضور بيش از اندازه يرندكان در منطقة شهررى، مىتواند عاملى

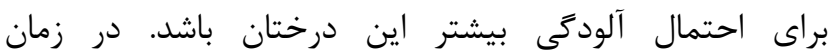
نمونه مشهود بود.

در مجموع با توجه به اينكه اين مطالعه، اولين مطالعه

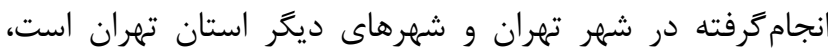
ضمن اينكه تا حدودى وضعيت إيدميولوزى گونههاى قارج كريبتوكوكوس و بلويزه كريبتوكوكوس كتىى را نشان مى مدهد اما نتايج اين تحقيق نمىتواند وجود قارج كريبتوكوكوس ترتيى در اين

5. Pal M, Boru BG. Natural habitat of Cryptococcus neoformans. J Nat Hist. 2010;6(1):5-8.

https://www.researchgate.net/profile/Mahendra Pal2/publication//Natural-habitat-ofCryptococcus-neoformans.pdf

6. Springer DJ, Chaturvedi V. Projecting global occurrence of Cryptococcus gattii. Emerg Infect Dis. 2010;16(1):14

https://doi.org/10.3201/eid1601.090369 PMID:20031037 PMCID:PMC2874352

7. Salehei Z, Mahmoudabadi AZ, Zarrin M. Lack of Cryptococcus gattii from Eucalyptus in Ahvaz. Curr Med Mycol. 2015;1(1):1-3. https://doi.org/10.18869/acadpub.cmm.1.1.1 PMID:28680973 PMCID:PMC5490314

8. Kidd SE, Chow Y, Mak S, Bach PJ, Chen H, Hingston AO, Kronstad JW, Bartlett KH. Characterization of environmental sources of the human and animal pathogen Cryptococcus gattii in British Columbia, Canada, and the Pacific Northwest of the United States. Appl Environ Microbiol. 2007;73(5):1433-43 https://doi.org/10.1128/AEM.01330-06 PMID:17194837 PMCID:PMC1828779 
9. Huérfano S, Castañeda A, Castañeda E. Experimental infection of almond trees seedlings (Terminalia catappa) with an environmental isolate of Cryptococcus neoformans var. gattii, serotype C. Rev Iberoam Micol. 2001;18(3):131-2. PMID: 15487923

10. Ren P, Springer DJ, Behr MJ, Samsonoff WA, Chaturvedi S, Chaturvedi V. Transcription factor STE12 $\alpha$ has distinct roles in morphogenesis, virulence, and ecological fitness of the primary pathogenic yeast Cryptococcus gattii. Eukaryot Cell. 2006;5(7):1065-80. https://doi.org/10.1128/EC.00009-06 PMID:16835451 PMCID:PMC1489290

11. Springer DJ, Ren P, Raina R, Dong Y, Behr MJ, McEwen BF, et al. Extracellular fibrils of pathogenic yeast Cryptococcus gattii are important for ecological niche, murine virulence and human neutrophil interactions. PLoS One. 2010;5(6):e10978.

https://doi.org/10.1371/journal.pone.0010978 PMID:20539754 PMCID:PMC2881863

12. Bineshian F, Zaini F. Study of Cryptococcus neoformans var. gattii from Eucalyptus camaldulensis in some northern regions of Iran. Koomesh. 2002;3(1):59-67.

13. Kamari A, Sepahvand A, Mohammadi R. Isolation and molecular characterization of Cryptococcus species isolated from pigeon nests and Eucalyptus trees. Curr Med Mycol. 2017;3(2):20-5.

https://doi.org/10.29252/cmm.3.2.20 PMID:29354777 PMCID:PMC5763894

14. Nowrozi H, Kazemi A, Mohammad Ganji Nik B, Sabokbar A. Isolation of Cryptococcusneoformans var. gatti from Around of Eucalyptus trees in Different Regions of Iran. Sci J Ilam Uni Med sci. 2016;23(7):1-8.

15. Illnait-Zaragozí M, Martínez-Machín G, Fernández-Andreu C, Perurena-Lancha M, Theelen B, Boekhout T, et al. Environmental isolation and characterisation of Cryptococcus species from living trees in Havana city, Cuba. Mycoses. 2012;55(3):e138-44. https://doi.org/10.1111/j.1439-

0507.2012.02168.x PMID:22364253
16. Ergin Ç, Ilkit M, Hilmioğlu S, Kaleli I, Demirci M, Kaya S. The first isolation of Cryptococcus neoformans from Eucalyptus trees in South Aegean and Mediterranean Regions of Anatolia in Turkey despite Taurus Mountains alkalinity. Mycopathologia. 2004;158(1):43-7. https://doi.org/10.1023/B:MYCO.0000038431.7 2591.7e PMID: 15487319

17. Hamasha AM, Yildiran ST, Gonlum A, Saracli MA, Doganci L. Cryptococcus neoformans varieties from material under the canopies of eucalyptus trees and pigeon dropping samples from four major cities in Jordan. Mycopathologia. 2004;158(2):195-9. https://doi.org/10.1023/B:MYCO.0000041840.3 4011.23 PMID: 15518348

18. Randhawa H, Kowshik T, Chowdhary A, Preeti Sinha K, Khan Z, Sun S, et al. The expanding host tree species spectrum of Cryptococcus gattii and Cryptococcus neoformans and their isolations from surrounding soil in India. Sabouraudia. 2008;46(8):823-33. https://doi.org/10.1080/13693780802124026 PMID: 18608895

19. Halliday CL, Carter DA. Clonal reproduction and limited dispersal in an environmental population of Cryptococcus neoformans var. gattii isolates from Australia. J Clin Microbiol. 2003;41(2):703-11.

https://doi.org/10.1128/JCM.41.2.703-711.2003 PMID:12574270 PMCID:PMC149711 